\title{
El pensamiento romántico de Joan Maragall
}

\author{
The Romantic Thought of Joan Maragall \\ MAGDALENA BOSCH RABELL \\ Universitat Internacional de Catalunya
}

Recibido: 20/04/2017 Aceptado:14/02/2018

\section{RESUMEN}

Este artículo analiza la recepción del Romanticismo en la obra de Joan Maragall. A través de sus escritos, de los críticos que la han estudiado y de los epistolarios; se estudia la trayectoria que le predispuso a esa recepción; las similitudes con el krausismo, a la vez que su independencia de él y las lecturas directas de autores considerados románticos. Más concretamente se muestra cómo Maragall desarrolló una teoría estética inspirándose en autores del Círculo de Jena. Esta influencia explica la naturaleza de su espiritualidad y su pensamiento religioso; así como el ascendiente que tuvo entre poetas españoles cercanos y más jóvenes.

PALABRAS CLAVE

MARAGALL, ROMANTICISMO, CÍRCULO DE JENA, ESPÍRITU, ESTÉTICA

\begin{abstract}
This article analyses the reception of Romanticism in Joan Maragall's work. His personal career path inclined him to this sensitivity. This predisposition is studied through his works, his critics and his personal letters. Similarly, his affinity to Krausism, his independence from it, and direct readings of Romantic authors are studied. More accurately, his inspiration by Jena's Circle authors for his aesthetic theory is showed. This influence is the very reason of his spiritual style, his religious thought and his influence on some younger Spanish poets.
\end{abstract}

KEYWORDS

MARAGALL, ROMANTICISM, JENA'S CIRCLE, SPIRIT, AESTHETICS

(C) Contrastes. Revista Internacional de Filosofía, vol. XXIII-Nº1 (2018), pp. 59-76. ISSN: 1136-4076

Departamento de Filosofía, Universidad de Málaga, Facultad de Filosofía y Letras

Campus de Teatinos, E-29071 Málaga (España) 


\section{UNA PERSONALIDAD PROCLIVE AL ROMANTICISMO}

JoAN MARAGaLL (1860-1911) ES SIN DUDA uno de los escritores catalanes que cuenta con más reconocimiento, también fuera de Cataluña. Su personalidad estuvo marcada por una trayectoria profesional singular, que le otorga los primeros tintes románticos: la lucha interna entre su deseo de ser poeta y su deber de ser abogado para dirigir los negocios de su padre. Estudió Derecho por insistencia de su progenitor y empezó a trabajar en la empresa familiar, mientras escribía poesía a escondidas. Por salvar el negocio paterno ejerció de abogado para él. Lo hizo movido por un sentido del deber filial, pero en contra de sus gustos personales. Resueltos los problemas, abandonó definitivamente el ejercicio de la abogacía y nunca habló de estos acontecimientos ${ }^{1}$.

Las biografías escritas por quienes le conocieron más de cerca subrayan la sencillez de su personalidad: «un hombre buenísimo, extremadamente correcto, de trato admirable, fidelísimo; un excelente caballero, agradabilísimo, de respuestas obvias, de actuaciones justificadas, de reacciones normalísimas. Sin embargo, llegaba el momento en que se interponía entre el poeta y su interlocutor la poesía. Entonces se transfiguraba, entraba en una especie de estado de gracia»... ${ }^{2}$ Fue firme en sus convicciones, entre las que se encuentra un marcado catalanismo, que se podría clasificar más en la línea romántica de amor a la patria, algo idealizada, que en aspiraciones políticas concretas. Sin embargo, su artículo «La patria nueva» casi le cuesta la cárcel.

Aunque popularmente ha sido más conocido como poeta fue también un pensador, en el sentido genuino del término. Es llamativo el ascendiente que tuvo, no sólo en la sociedad catalana de finales del XIX; sino también entre intelectuales y poetas españoles a quienes inspiró gran respeto y en algunos casos una franca amistad. Su correspondencia con Unamuno, la admiración que despertó en Dámaso Alonso, o la valoración que hace de su obra Laín Entralgo son ejemplos de la presencia de su figura en el Pensamiento español y también de su relevancia como ensayista. Su prosa le ganó también el prestigio personal entre sus contemporáneos y entre los artistas de la siguiente generación; como el ya citado Dámaso Alonso, o Juan Ramón Jiménez.

Entre los años 1890-1911 publicó regularmente artículos de opinión en el que entonces fuera el periódico más leído en Barcelona. En aquellos ensayos analizaba acontecimientos sociales y culturales, desde una especie de «sentir común» popular, pero a la vez basado siempre en un buen conocimiento de la cultura europea contemporánea. Fue muy avanzado: tradujo a Nietzsche

1 M. Serrahima, Vida i obra de Joan Maragall. Bruguera: Barcelona, 1966, p. 29.

2 Testimonio de Francesc Pujols, en J. Pla, Joan Maragall un assaig. Destino: Barcelona, 1984, p. 66. 
y a Goethe; leyó a Novalis, Schiller y Schelling ${ }^{3}$. Su perfil intelectual está marcado por el romanticismo idealista: una denodada búsqueda de lo espiritual, la visión esperanzada de la humanidad y de su dimensión fraterna, ideales morales elevados y un espíritu poético que impregna toda su obra, también la prosa.

\section{El ROMANTICISMO de MARAgALl nO ES KraUSiSta}

El krausismo penetra en el ámbito de la cultura española en la segunda mitad del mil ochocientos. Karl Christian Friedrich Krause (1781-1832) había iniciado un movimiento ideológico que defendía los ideales de la humanidad y un cierto panteísmo en el que Dios está conteniendo dentro del universo, a la vez que lo trasciende. Sus ideas toman impulso y son difundidas gracias a la Institución Libre de Enseñanza (1876-1936), liderada por Julián Sanz del Río, a quien sucedió Francisco Giner de los Ríos. Son muchos los intelectuales españoles que recibirán este legado ideológico.

Por lo que se refiere a Joan Maragall, su obra transcurre casi al mismo tiempo en que la Institución forma a sus jóvenes. Si bien algunos aspectos de su pensamiento responden al prototipo krausista, no hay fundamento histórico para considerarle dentro de este movimiento cultural. Trías lo niega explícitamente ${ }^{4}$ y su biografía pone en evidencia que no congenió especialmente con Giner de los Ríos:

Yo he conocido a D. Francisco Giner de los Ríos, que ha venido aquí a pasar estas vacaciones con el empeño de enterarse del movimiento catalán. No se si se ha ido muy enterado, pero es un hombre muy simpático y menos solemne de lo que yo me figuraba. Estuvo en casa y me hizo muchas preguntas sobre el "movimiento religioso y filosófico de Catalunya". Le dije que no había nada de esto, como es un hecho. - ¿Qué entienden Uds. por nación catalana?- pues verá... no lo sabemos de modo preciso... un montón de cosas... 5

3 He tratado en otro lugar del conocimiento de la obra de Schelling por parte de Maragall. Véase: M. Bosch «Schelling i Maragall. Vida a l'art i a la paraula», Zeitschrift für Katalanistik, XIX (2006), pp.197-211. Allí hago alusión a un hallazgo inopinado en la biblioteca personal de Maragall, conservada en el Arxiu Maragall: encontré la edición en español de la obra de Schelling Bruno o del principio divino y natural de las cosas. Madrid: Biblioteca Económica Filosófica, 1881, vol. IV. Las primeras páginas del libro fueron subrayadas por el poeta.

4 Cf. E. Trías, El pensamiento de Juan Maragall. Barcelona: Fundación Banco Urquijo-Edicions 62, Col.lección: Biografies de catalans, 1982.

5 Carta a Roura, 4. I. 1898, Obra Completa, Edición de los hijos, por Sala Parés Llibreria, (en adelante: O.C.) Vol. IV, p. 175 (Original en catalán, traducción mía) 
La visita de Giner de los Ríos a Maragall no deja de ser significativa y desde luego prueba del ascendiente y prestigio del escritor catalán. A la vez, muestra que el líder de la Institución intuía ciertas afinidades entre ambos. En cualquier caso resulta claro que no hubo más que algunas entrevistas entre ellos, y que las similitudes que puedan descubrirse son más bien parte de un fondo común cultural en el que late el germen alemán de la revolución romántica.

Corredor ha estudiado estas afinidades. Considera que «obras como l'Oda Infinita, Excèlsior o l'Himne Ibèric se prestan a ver ciertas aspiraciones comunes con el sentido humanista sin las barreras ni limitaciones de los Krausistas. Sin embargo, a pesar de los interesados, la identificación de conceptos y aspiraciones no podía ser completa». ${ }^{6}$ Trías es muy preciso: En primer lugar, afirma la existencia de un malentendido causado por d'Ors, que afirmaría la pertenencia, al menos intelectual, de Maragall al krausismo. El filósofo catalán de siglo veinte desmiente con rotundidad tal afiliación: «nada más ajeno a él que la concepción espiritualista-racionalista más cercana al Hegel maduro que a Schelling. Mientras para Krause i para Hegel el alma es sólo un estadio en la autoconstitución del espíritu racional, para Maragall el espíritu racional es la expresión por elevación del único sujeto antropológico, que es el alma del mundo, no el espíritu. Su parentesco con Schelling y Novalis queda así confirmado». ${ }^{7}$

Por un lado queda claro que Maragall no pudo formarse en el seno de la Institución libre de enseñanza, ni formó parte de la asociación. Y por otro lado, la influencia alemana que Giner de los Ríos recibe de Krause y divulga en España, es para el poeta barcelonés un legado que él recibe directamente de los autores que lee: Novalis, Schiller, Goethe, Schelling... Tenemos constancia de una afinidad personal de nuestro escritor con los autores que pertenecen a ese Círculo de amigos que iniciaron la revolución romántica en casa de los hermanos Schlegel, en Jena (1800-1805). Es además esta corriente concreta dentro del Romanticismo la que más influencia y duración tendrá en su pensamiento. La recepción de este grupo de filósofos y escritores se plasma muy marcadamente en los Elogios, que son obras de madurez.

Por esto y con razón se ha asociado a Maragall con el Romanticismo. Pero ya no como una colección de rasgos que podamos enumerar, sino como un espíritu común que se trasluce en la prosa, en la poesía y hasta en las cartas a sus amigos. Hasta el punto que Serrahima ha visto que la inclinación «romántica» del poeta es en realidad algo anterior a las lecturas de autores románticos. Más allá de la influencia de Novalis y otros, vemos una inclinación

6 Cf. J. M. Corredor, De casa i d'Europa. Barcelona: Selecta, 1971, pp. 174-5.

7 E. Trías, El pensamiento de Juan Maragall, op.cit., p. 83. 
natural que se revela, por ejemplo, en un poema relativamente temprano: la Oda Infinita ${ }^{8}$ (1888). No se trata, por tanto, de unas características que aparezca superficialmente, alguna vez; sino de un pensamiento y una sensibilidad que constituyen un carácter, un perfil intelectual coherente y que permanece especialmente a lo largo de los veinte últimos años de su vida, en la madurez de su obra.

Entre los contemporáneos de Maragall se establecen comparaciones y a veces confusiones, entre Modernismo y Romanticismo. Él mismo considera que el Romanticismo fue el Modernismo de la generación de artistas de los años cuarenta. ${ }^{9}$ Luego acoge personalmente parte de esa herencia y su «Modernismo», que en su caso es más bien un acentuado Romanticismo. También en este punto se suceden las opiniones, por lo general convergentes. Aunque no faltan quienes arrastren la idea de que fue considerado en su tiempo un Modernista y así lo atestiguan, ${ }^{10}$ destaca sobre todo la autenticidad que todos le reconocen. Es decir, que si hay afinidades de la obra de Maragall con alguna escuela o corriente de pensamiento, es por coincidencia, porque sencillamente se da el hecho de que comparte tal rasgo o modo; pero la sinceridad de su obra, la coherencia de sus escritos con su pensamiento, la fidelidad a su propia sensibilidad, están fuera de duda. Se podría aplicar a Maragall lo que él mismo afirma de otro artista: «consideró el Modernismo en aquello que respondía a los impulsos de su alma». Es decir, no hay imitación ni adopción de posturas que no respondieran a algo auténtico. Él tenía su propio pensamiento y su propio estilo, que respondía a algo personal y pensado, nunca a modas. ${ }^{11}$

Esta vibración romántica en el momento en que Maragall publica sus artículos, le señala como una personalidad fuerte e independiente. Ilustra su singularidad la reflexión que hace Josep Pla, precisamente resaltando su originalidad:

Hay algo sorprendente, en efecto, en la poesía de Maragall: es un poeta que escribe una poesía que no tiene nada que ver con la poesía de su tiempo- de aquí y fuera de aquí. Su temática es optimista y exultante. Maragall está fuera de la temática poética de su tiempo. Acepta la vida tal como es, impávidamente (como Goethe), y considera que la existencia es una cosa tan enorme, tan decisiva, que el mero hecho de vivir es para el la esencia de la felicidad, la constatación definitiva. Es un hombre feliz y, por tanto, un poeta feliz. ${ }^{12}$

8 M. Serrahima, Vida i obra de Joan Maragall, op.cit., p. 57.

9 «Vicente Cuyás y la Fattuchiera», 8. III. 1899, O. C., Vol X, p. 41.

10 J. Ferrán, Los diálogos de Juan Maragall. (Colección vida y pensamiento españoles). Madrid: Ed. Nacional, 1971, p. 25.

11 «José Soler y Miquel», 18. III. 1898, O. C., Vol. X, p. 32.

12 J. Pla, Joan Maragall un assaig, op.cit., p. 106. (Original en catalán, traducción mía). 
Además de definir su carácter personal, Pla establece un contraste respecto de los llamados «poetas malditos». La exaltación de la vida, la alegría y la espiritualidad son rasgos típicos de autores anteriores, pero en contraste con el estilo de sus contemporáneos. Rimbaud y Verlaine «inauguraron el mito de esta maldición que tiene por base la pederastia, el alcoholismo, la cárcel, el hospital, el erotismo frenético y la miseria». ${ }^{13}$ Esta lejanía respecto de sus coetáneos refuerza aún más la personalidad propia, la inspiración personal, y la influencia directa de los autores alemanes.

En este marco de la inspiración personal también se debería añadir algo que va más allá de la influencia germánica y del Modernismo: las deudas de Maragall con la Cultura clásica, de la que demuestra con frecuencia un buen conocimiento. Platón y Dante son nombrados al inicio del elogio del amor, como una de las muchas muestras de su bagaje clásico, filosófico y literario. ${ }^{14}$

\section{LeCtuRAS DEL CírCulo de JeNA y otros aUtores ALEMANES}

Uno de los autores en el que se suele reconocer una influencia sobre Maragall es Nietzsche. Sobre la relevancia que debe reconocerse a esta influencia hay discrepancias. A unos parece que es un impacto ocasional ${ }^{15}$, otros conceden a su vitalismo el predominio en su obra y lo consideran de clara inspiración Nietzscheana. Trías considera el filósofo de Röcken, junto con Goethe, «mentores espirituales» del escritor catalán ${ }^{16}$.

Sin embargo los que coinciden en subrayar el protagonismo de Nietzsche, se refieren siempre al Compte Arnau, obra en la que destaca el fondo vitalista y en la que el protagonista encarnaría al hijo de la tierra y súper-hombre ${ }^{17}$.

Contamos con dos artículos para conocer de primera mano la opinión que merece a Maragall la obra del vitalista alemán. Uno es de 1893 y contrasta con el siguiente, el obituario de 1900. El primero es eminentemente elogioso. Pondera el vitalismo nuevo y revitalizador, el optimismo y la fuerza regeneradora. El león que ríe es visto por Maragall como el símbolo de una voluntad de poder que podría sacar de su inercia a la clase burguesa. El superhombre podría romper las dinámicas sociales estancadas, que no permiten avanzar y se quedan anquilosadas. «El radicalismo aristocrático de

13 Ibid., p. 106. (Original en catalán, traducción mía).

$14 C f$. E. Trías, El pensamiento de Juan Maragall, op.cit., p. 73.

15 E. Bou, «La llum que ve del nord», Barcelona: Claret, 1997, p.7. Este mismo autor la misma valoración de la influencia de Nietzsche en un ensayo más reciente: «Amor redemptor? Visions urbanes de Joan Maragall». En J. M. Terricabras (ed.), Joan Maragall, paraula i pensament. Girona: Documenta Universitaria. Càtedra Ferrater Mora, 2011, pp. 237-257.

16 E. Trías, El pensamiento de Juan Maragall, op.cit., p. 32.

$17 C f$. M. Guitart-Ribas, Influencias alemanas en la obra de Juan Maragall. Washington D.C.: Dissertation Information Service. The Catholic University of America, 1988. 
Nietzsche, con toda su genial brutalidad, nos refresca y nos infunde consuelo y fortaleza ${ }^{18}$. Sin embargo, siete años más tarde su opinión ha cambiado:

Nietzsche era un sediento de absoluto, un sediento de Dios; pero no quiso bajarse a beberlo en la fuente de la fe, y murió de sed. Una gran potencia que había en su espíritu le hizo soberbio como no puede serlo un hombre: el límite de nuestra razón y de nuestros sentidos lo despreció y quiso comprender lo incomprensible, lo que hay que presentir y adorar con humildad. No vio la altísima dignidad que encierra esa humildad humana que puede orar trémula y ansiosa en su presentimiento de lo eterno... ${ }^{19}$

En ese artículo de 1900 Maragall refleja su impresión de la lectura de Así habló Zaratustra. A la vez que sigue reconociendo fuerza y grandeza en su autor, manifiesta el daño que produce la falta de medida, ponerse en lugar de Dios, emprender modos destructivos. Lamenta que su superhombre se muestra «con calma de creador, no con acento sereno de triunfo, sino con gestos desacompasados, a gritos desgarradores, como para ahogar ese otro grito interno que no se acalla y le dice: No basta; ¡más! ¡más!».20

El escritor catalán prefería la vitalidad serena. Lo auténtico y sincero pero espiritual y lleno de paz. Es más bien el estilo de Novalis, a quien ya hemos nombrado y con quien mantiene mayor y más constante afinidad. Hemos aludido antes a la altura espiritual que admira en él y que considera muy por encima de lo corriente. Lo ha estudiado con detalle Enric Bou $^{21}$ y lo señala también Eugenio Trías, como una presencia especialmente manifiesta en los elogios y en toda su estética de la palabra viva ${ }^{22}$.

Sobre la idea de artista y, más concretamente de poeta, son varios los aspectos que Maragall comparte con autores alemanes, especialmente con Goethe y Schiller, y más marcadamente con este último. El hombre es objeto, no sólo sujeto de poesía. En el Elogio de la poesía asume la idea de Schiller de que el signo desaparece. También para Shelling importa el símbolo y su significado, mucho más allá de la materia. Y todavía más claramente en Novalis, para quien Enrique de Ofterdingen es sacerdote e intérprete, especialmente a través de la palabra ${ }^{23}$.

18 «Federico Nietzsche», Febrero 1893, O. C., vol. X, p. 99.

19 «Federico Nietzsche», 19. XI. 1900, O. C., vol. X, p. 101.

20 Ibid., p. 102.

21 E. Bour, La llum que ve del nord, op.cit., pp. 5-14

22 Cf. E. Trías, El pensamiento de Juan Maragall, op.cit., p. 67

23 Cf. L. Quintana Trías, La veu misteriosa. Barcelona: Publicacions de l'Abadia de Montserrat, 1996, pp. 120 i ss. 
Tenemos constancia autobiográfica de la fuerte impresión que causó en Maragall la lectura de Schiller, desde las lecturas compartidas con su amigo Roura $^{24}$, hasta los empeños también acompañados de traducir los textos alemanes. De su intuición y facilidad en traducir el poeta catalán hace alarde abierto en carta a su amigo ${ }^{25}$. No sabemos si leyó el Tratado de la gracia y la dignidad, pero en su elogio a la gracia encontramos similitudes respecto del alemán. Especialmente, en esa peculiaridad de considerarla algo espontáneo, pero que no es fruto del instinto sino del espíritu ${ }^{26}$.

Nos consta que además de leer obras de Schiller como Guillermo Tell o Wallenstein; leyó Wagner: Maestros cantores de Nüremberg, la Valquiria, Tamhäuser...y anotó el Werther, de Goethe. ${ }^{27}$

$\mathrm{Su}$ relación con Goethe comienza por la admiración y en un arrebato de entusiasmo: compra un retrato que coloca en su despacho ${ }^{28}$. Habla con sus amigos sobre el escritor alemán ${ }^{29}$, le admira porque crea «personajes con luz $\rangle^{30}$, porque es un verdadero artista que «conscientemente asciende por el camino de la belleza $»^{31}$, pero sobre todo aprecia «el sentido de la vida que late en su obra: el optimismo, un mundo que es para bien porque es bello; incluso Fausto, después de sumergirse en lo más hondo de la vida, sólo se satisface en el sueño de una humanidad fuerte, libre y serena» ${ }^{32}$, «lo trágico del final queda siempre circundado de una aureola de gloria que parece redimir todo el mal de la catástrofe, y consuela, y comunica una esperanza fortalecedora» ${ }^{33}$.

Josep Pla ha recogido también su testimonio directo, la opinión personal de Maragall expresada por sí mismo:

[...] en la vida i la formación de Goethe la obsesión greco-latina és su viaje de ida. Después está el segundo proceso, el segundo viaje, el de vuelta: cuando Goethe, enormemente vital, sano, tumultuoso, pasa por encima de los moldes de la retórica y de la pauta y procura tener una idea más profunda de las cosas de la vida -en el sentido más vasto de la palabra. Este es mi Goethe, el de vuelta, el del segundo Fausto. ${ }^{34}$

$24 C f$. Carta a Roura, 4.V.1890, O.C., Vol. IV, p. 66.

$25 C f$. Carta a Roura, 29.V. 1890, Vol. IV, p. 74.

$26 C f$. «Elogio de la gracia», O. C., Vol. III, pp. 180-2.

27 Cf. A. Terry, La poesia de Joan Maragall. Barcelona: Ed. Barcino, 1963, p. 181.

28 Carta a Roura, 4.V.1890, O. C., Vol. IV, p. 65.

29 Carta a Roura, 22. X.1890, O. C., Vol.IV, p. 78.

30 «Goethe», 1899, O.C., Vol. X, p. 60.

31 Ibíd., p. 61.

32 Ibid.p. 62.

33 Ibid.p. 63.

34 J. Pla, Joan Maragall un assaig, op.cit., p. 79. 
Estas son las impresiones cercanas a las que quedan reflejadas en su artículo de 1899. Sin embargo, una carta de 1904 dirigida a un amigo atestigua un cambio importante en su valoración. En ella declara que ha admirado y admira a Goethe, pero al mismo tiempo ve con más claridad la tara racionalista presente en toda su obra y el modo externo en que él y sus contemporáneos de siglo XVIII trataron el arte ${ }^{35}$.

Hemos aludido también a Wagner. Conocemos la reflexión que le sugiere las representaciones hechas en nuestro país. En 1891 celebra que se ha dado a conocer algo nuevo: los conciertos de Tristán e Isolda, Maestros Cantores ${ }^{36}$, cinco años más tarde traduce la primera de estas obras y se lamenta de lo flojo que le parece Wagner como poeta ${ }^{37}$. Más adelante, ya en 1899 , hace una valoración de las representaciones que se han hecho de las óperas de Wagner en ámbito español. Lamenta la dificultad del idioma, la poca comprensión del público; y sobre todo aclara el significado de la ópera como arte integral, la necesidad de entender el texto y la interpretación teatral además de apreciar la música y el canto ${ }^{38}$. Pero como músico, tampoco Wagner fue su principal favorito, sino que parece que su preferencia se inclinó por Mozart ${ }^{39}$.

Pero el conocimiento y aprecio de Maragall por la cultura alemana no acaban en los autores mencionados. En su artículo sobre Novalis el poeta catalán expresa verdadera estima y elogia vivamente el espíritu de Jorge Federico de Hardenberg. Pondera especialmente que fue muy espiritual, un verdadero espíritu poético, muy elevado. Justifica que Schlegel, Schleiermacher y Steffens le llamaran el «divino» y cita a Carlyle afirmando que «su espiritualidad arrebataba su pensamiento hacia un mundo mejor» ${ }^{40}$. Se demuestra buen conocedor de su obra. Más allá de la traducción de Enrique de Ofterdingen. En él descubre el valor universal de lo romántico. Ve en sus ideas como gérmenes de verdad que pueden traer con el tiempo frutos magníficos. Y consiera que el joven poeta alcanzó un «estado de poesía» ${ }^{41}$.

Además de citar algunos símbolos típicos como la flor azul, o los paralelismos que se pueden observar entre la cueva de Enrique de Ofterdingen y la fageda d'en Jordá ${ }^{42}$, hay algunos contenidos que se repiten: «Novalis habla del conocimiento de la ciencia de la Historia humana y de los caminos

35 Carta a Pijoan, 15. VI. 1904, O.C., Vol. XXIII, p. 79.

36 Carta a Roura, Octubre 1891, O. C., Vol. IV, p. 88.

37 Carta a Roura, 20. VI.1896, O. C., Vol. IV, p. 159.

$38 C f$. «Sobre un drama de Wagner», 23. XI de 1899, O. C., Vol. X, p. 63 y «Wagner fuera de Alemania», 6. XII.1899, O. C., Vol. X, p. 68.

39 J. Pla, Joan Maragall un assaig, op.cit., pp. 50-51

40 «Novalis», 1901, O.C., Vol. X, p. 131

41 «Novalis», O. C., Vol. X, p. 132

42 M. Guitart-Ribas, Influencias alemanas en la obra de Juan Maragall, op.cit., p. 131. 
para llegar a él. Maragall nos presenta una idea similar cuando hace mención de los tres grados de sinceridad en el hablar [...] Ambos escritores tienen en mente al poeta en su búsqueda de la expresión adecuada para llegar al corazón del hombre» ${ }^{43}$

Schelling puede considerarse cercano a Novalis en la inspiración más constante y determinante para la creación de los elogios. Como hemos mencionado anteriormente, nos consta la lectura directa que hizo de algunos de sus textos, pero además es innegable que ambos autores se encuentran inmersos en una cultura romántica común. Esta afinidad da lugar a coincidencias de relieve. Por ejemplo, en la comprensión de la ley como algo interno y libre. Es algo que tratan sus contemporáneos, que Schiller tematiza a fondo con su definición de belleza como libertad en su aparecer; pero que Schelling y Maragall parece compartir muy estrechamente en estos fragmentos que reproducimos.

Para Schelling la forma es una ley interna, medidas que uno se da a sí mismo; luego libres:

En la naturaleza la forma nunca se define y determina como una negación, sino como una afirmación. Bien es verdad que por lo general pensamos la figura de un cuerpo como una limitación que este tiene que sufrir; pero si pudiéramos llegar a ver la fuerza creadora nos resultaría obvio que es una medida que la figura se impone a sí misma y en cuyo seno ella aparece como una fuerza verdaderamente inteligente. Pues, en efecto, la capacidad de otorgarse uno a sí mismo sus propias medidas siempre se ha considerado como una excelencia, incluso como la más elevada de todas ${ }^{44}$.

Para Maragall la libertad natural es la ley, porque es vida dentro de la cosa:

La ley no era una cosa externa, no implicaba una descomposición del mundo; la esencia misma era la ley: no era algo que ata; al contrario: la libertad natural de las cosas era su ley. ¡Y qué hermosa aplicación en seguida al concepto del arte! La ley del arte no es una ley dura, sino tan propia y tan íntima que se confunde con el ritmo de la vida... ${ }^{45}$

43 Ibid., p. 85.

44 F. W. J. Schelling; Discurso de la Academia o Sobre la relación de las artes plásticas con la Naturaleza, (trad. A. Leyte y H. Cortés). Madrid: Biblioteca Nueva, 2004, p. 129. (SW VII, 303)

45 «Dulce ley», 14.XI. 1905, O. C., Vol. XVIII, p. 194. 
Esta idea de la emergencia desde dentro, para la ley y para la forma; para la belleza en definitiva, es una de las claves de su Teoría de la Palabra viva. La obra de arte representa siempre la emoción artística sincera del poeta y «redime al alma de toda contingencia». Sólo la música «encuentra el elemento natural y lo muestra con su expresión propia». La expresión poética y la musical se parecen en que «generadas ambas en el ritmo de la eternidad llevan su imprenta originaria». ${ }^{46}$ La cercanía de Maragall a Schelling es llamativa ${ }^{47}$.

Trías considera que la concepción maragalliana del amor es a la vez principio y derivación de su teoría estética. La inspiración, la fuerza creadora, la vibración poética; siempre tienen su inicio en algún modo de enamoramiento. Se da una original síntesis filosófica sobre la herencia de Schelling, Novalis, y sus seguidores anglosajones ${ }^{48}$. Vemos que son muchas las ideas propias de los personajes que formaron parte del Círculo de Jena y que Maragall refleja de varias maneras: apreciar todo lo que represente un anhelo sincero de altura ${ }^{49}$, la idoneidad del artista para profesar cualquier ciencia de la vida ${ }^{50}$, cómo el arte exige unidad y no es tal arte si es fragmentario ${ }^{51}$, cómo esa unidad es propia de la fuerza creadora: «Para el artista, todo venía a ser igual, porque en la variedad de los objetos no veía sino grados o modos de la única fuerza creadora de todos ellos manifestado por las líneas que su ritmo producía en cada una» ${ }^{52}$.

Por otro lado Maragall no se adentra en un idealismo desvinculado de la realidad. A la vez que la grandeza y la más elevada belleza, busca también lo cotidiano los detalles de la vida corriente; como cuando habla de una vaca, de la retama o de las criadas que duermen en la leyenda del Comte Arnau. Además, él mismo nos advierte del peligro de la ensoñación: «Sólo de lejos el humano anhelo de la belleza suma podrá pareceros una majestuosa elevación coronada de cimas excelsas. Sabed que en su majestad serena se contienen muchos devaneos, muchas inquietudes y tormentos, y que alrededor de las

$46 C f$. «El drama musical de Mozart», 8. II. 1905, O. C. Vol. XX, pp. 10-12.

47 «Maragall es muy cercano en estos escritos al Schelling de 'La relación de las artes figurativas con la naturaleza'; después la belleza del arte: la humana expresión de la belleza: la poesía es el arte de la palabra (...) como trata el origen del arte en el elogio de la danza: Amor a la forma creadora: este deseo que Platón definía como aspiración a engendrar en la forma de la belleza.» (Trad. mía) Cf. E. Trías, El pensamiento de Juan Maragall, op.cit., p. 67-70.

48 Ibid., p. 72.

49 «Ruskin», 19. II. 1903, O. C., Vol. XVIII, p. 185.

50 «Prosa y verso», 23.I.1902, O. C., Vol. XVIII, p. 127.

51 «Un libro fuerte e incompleto», 13. XI. 1902, O. C., Vol. XVIII, p. 162.

52 «Impresión de la exposición Sunyer», Julio 1911, O. C. Vol. XVIII, p. 20. 
cimas que brillan al sol más altas, hay los mayores y más oscuros abismos». ${ }^{53}$ El anhelo de belleza no debe alejarnos de la realidad, no debemos dejarnos engañar por la apariencia de lo grandioso. Pero la actitud realista ha de ir de la mano de la búsqueda del ideal. El que no anhela un más allá «no es ya un hombre para los demás hombres: no es poético, porque no es humano». ${ }^{54}$

La lectura atenta y apreciativa de autores alemanes por parte de Maragall se extiende aún más: los menciona en sus críticas, comparte ideales románticos. La lista de autores va creciendo a medida que nos adentramos en el pensamiento del autor catalán, comprendiendo a Tieck y Schlegel entre otros $^{55}$.

\section{RASGOS ROMÁNTICOS EN EL PENSAMIENTO DE MARAGALL}

La obra de Joan Maragall va más allá de la poesía sola. Además de una extensa obra en prosa, compuesta por los elogios y numerosos artículos de prensa; hay un estilo reflexivo que impregna todo. Parece que al escribir, lo hace desde un pensamiento sereno y profundo, sea lo que sea eso que escribe. Por eso es pertinente preguntarse por su pensamiento. Algo parecido ocurre con otros poetas, cercanos en el tiempo, en los que encontramos este eco filosófico. Por esto «Algunos críticos [...] han considerado a Maragall, Miró y Juan Ramón como escritores cuya creación literaria es en buena parte expresión de una serie de cuestiones de marcado cariz filosófico»». ${ }^{56}$ En los últimos años y en especial, con motivo del aniversario del centenario de su fallecimiento se han multiplicado los estudios que le consideran como un filósofo y consiguen hacer cierta sistematización de su pensamiento ${ }^{57}$. El propio autor se muestra abierto a las interpretaciones que hagan los demás acerca de determinado ascendiente filosófico: no ha sido su intención, pero asume que esas semejanzas son posibles y comprende que otros establezcan comparaciones. ${ }^{58}$

53 «Poesía de otro tiempo», 19. II. 1903, O.C., Vol. XVIII, p. 186.

54 «A propósito de un poema», 8. V. 1902, O. C., Vol. XVIII, p. 140

55 Cf. G. Allegra, Maragall traduttore e interprete di Novalis, Estratto da Giornale Italiano di Filologia, XI (XXXII) 2. Roma: Gadamo editore, 1980.

56 J. L. Rodríguez Bravo, Palabra y Paraíso: La meditación poética de Joan Maragall, Gabriel Miro y Juan Ramón Jiménez. Dissertation Information Service, University of Wisconsin: Madison, 1987, p. 205.

57 Véanse especialmente las monografías: Terricabras (ed.), Joan Maragall. Paraula i Pensament, op.cit. y Casals y Talavera (coords.) Textos i contextos. I Congrés Internacional Joan Maragall. Bellaterra: Universitat Autónoma de Barcelona, 2012.

58 Carta a Lluís Lluís, en M. Serrahima, Vida i obra de Joan Maragall, op.cit., p. 59. 
Para ver qué pensaba el propio Maragall de su posible perfil filosófico, resultan muy ilustrativas las palabras que dedica a un escritor joven y que bien podemos pensar expresan su concepción personal de filósofo auténtico; más allá de las convenciones o catalogaciones:

Si por filósofo entendéis al hombre entretenido en formarse un concepto abstractamente sistematizado de la esencia de las cosas, y que fríamente procura ajustar todas sus manifestaciones a su sistema, digo desde ahora que estáis equivocados [...]. Pero si por filósofo entendéis un hombre fuertemente interesado en el misterio de la vida y entregado con todas sus potencias y sentidos, a la contemplación de este misterio y a comunicar en caliente los espasmos sufridos en esta contemplación y su resolución en conducta del espíritu individual y social [...] efectivamente, estas narraciones han brotado en aquella región del entendimiento en la que los tipos y las acciones externas se ven a la luz vaga y temblorosa del misterio de su esencia. ${ }^{59}$

Quizás en estas condiciones también él accedería a ser considerado un filósofo. Al menos por su interés en el misterio de la vida, por su penetrante contemplación del misterio y por la sinceridad con que lo comunica.

Es innegable que su obra está enteramente traspasada de reflexión. Dámaso Alonso explica bien en qué consiste este fenómeno: «El poeta, al ponerse a escribir, hondamente conmovido, quiere en realidad transmitir un mensaje, y ese mensaje es una mezcla de elementos conceptuales, afectivos e imaginativos». ${ }^{60}$ Por esto es difícil separar completamente la poesía del pensamiento, porque la creación poética no está desprovista de un contenido y de un significado. Y esto se agudiza en toda la obra en prosa, que también es poética. Quizás sea este uno de los rasgos de la obra maragalliana: la poesía a veces es filosófica y la prosa es siempre poética. Hay una unidad de poesía y pensamiento en los textos, porque se da esa unidad en la personalidad concreta del autor. ${ }^{61}$

59 «Contes d'un filòsof de Diego Ruiz», O. C., vol. XX, p. 124. (Original en catalán, traducción mía).

60 D. Alonso, Cuatro poetas españoles. (Garcilaso, Góngora, Maragall, Antonio Machado). Madrid: Gredos, 1962, p.106.

61 Esto sigue siendo cierto, especialmente entre los Elogios (1905-1911) y la mayoría de su poesía; a pesar de la incoherencia que Moreta señala entre los artículos en el «Diario de Barcelona» (periodo 1892-1903) y la poesía que escribía en esa misma época. En efecto, se advierte en esos años una falta de concordancia entre los artículos de ese periódico, sometidos a un exigente censor, dependientes de la aprobación de la burguesía; y su poesía más libre. Pero su pensamiento permanece y va encontrando su espacio de expresión. Como apunta el mismo autor, a partir de 1905 y 1906 hablará con mayor libertad; y del todo abiertamente en 1911. Cf. I. Moreta; «El pensament de l'últim Maragall» (1906-1911), en Terricabras (ed.), Joan Maragall 
Esta sinceridad o franqueza, lejana de la sofisticación y de falsas apariencias; ya es uno de los rasgos que podríamos considerar románticos: expresar las emociones tal como se sienten. Dejar que el alma vibre y se exprese según su inspiración. Este rasgo lo vemos, por ejemplo, en la teoría del arte de Schelling, que también considera que el verdadero artista es quien otorga a la obra la vida de su propia alma ${ }^{62}$. Para ambos autores, y en consonancia con el contexto de Jena, la vida es un impulso creador que se manifiesta en la belleza, en la forma, en la obra artística.

En Maragall el amor a las ideas se da junto al rechazo del racionalismo y del filósofo sólo conceptual, ajeno a las emociones. También en esto se parece al Romanticismo de Jena. Podemos recordar el Systemprogramm, firmado por Hölderlin, Schelling y Hegel, admirando la razón cuando es estética, cuando capta la belleza; pero rehuyendo la razón cuando es fría, mecánica y sin vida ${ }^{63}$. En la teoría de la palabra se da esta valoración del alma: la palabra lleva un mensaje, pero ella sola no es un todo; necesita especialmente del alma que la inspira y la comunica. A la vez, esta palabra es un don que hace posible la expresión adecuada del pensamiento. En este sentido Maragall rechaza la filosofía oscura, que no habla claramente porque emerge de una razón aislada: «los grandes pensadores siempre me causan el efecto de poetas incompletos que, teniendo una visión del alma del mundo, pero sin el don de la palabra para decirla, inventan palabras oscuras y atormentadoras del entendimiento para hacerse entender». ${ }^{64}$ Parece que este sería el mayor motivo para no considerarse a sí mismo un filósofo. Tampoco podemos dejar de ver que rehúye el estilo académico propio de un filósofo. Maragall vuelca en la escritura lo que corresponde a momentos poéticos fuertes, que son pocos; y sólo después puede hacer la reflexión de si aquello puede tomar tal o cual sentido filosófico, ético, moral. Este es el fondo teórico que va quedando plasmado en su obra, y más especialmente en su obra de los últimos años ${ }^{65}$, en los que desarrolla más plenamente su teoría poética y su teoría estética.

Otro rasgo que le acerca al «espíritu» de Jena, es su vitalismo; que en los últimos años «no es sólo una exaltación de la vida, sino la búsqueda de un lenguaje para expresar, de una manera muy elaborada y consciente, la necesidad

paraula i pensament, op.cit., pp. 283-314.

62 Sobre las semejanzas entre la «Teoria de la paraula viva» maragalliana y la Toeria del arte de Schelling, véase M. Bosch, «Schelling i Maragall. Vida a l'art i a la paraula», Zeitschrift für Katalanistik, XIX (2006), pp.197-211.

$63 C f$. «Das älteste Systemprogramm des deutschen Idealismus 1796/7?» (El sistema de programa más antiguo del Idealismo alemán).

64 Conversación con Pijoan, en: ARIMANY, Miquel; Maragall 1860-1911, Ed. M. Arimany: Barcelona, 1963; p.134. (Original en catalán, traducción mía).

65 I. Moreta, «El pensament de l'últim Maragall» (1906-1911), op.cit., p. 299. 
que tiene el ser humano de contar con un estímulo real para una acción siempre purificadora, siempre elevadora ${ }^{66}$. Se trata de una sensibilidad coherente con el romanticismo más idealista y positivo; cercano al esperanzado Schiller de «Los Artistas» o «Las palabras de la fe». Este rasgo coincide con su «credo estético», siguiendo el cual no exteriorizaba los momentos más negativos ${ }^{67}$. Responde a uno de los principios de su teoría poética, que dejó plasmado en «El derecho de hablar»:

Yo dudo; luego me callo. -Yo desespero; luego me callo. -Yo no tengo que decir más que lo que otros han dicho ya; pues me callo también. -Esto es lo que la conciencia dicta a todo hombre honrado. Porque el espíritu humano vive de afirmación y de esperanza y de originalidad; y por tanto, quien no tenga una fe o un presentimiento o un amor que dar no tiene derecho a ser oído. Espere en silencio para no contagiar la tremenda vanidad a sus hermanos. ${ }^{68}$.

Este vitalismo no es sólo cuestión de ese «código» al que nos referimos. Es tan constante en su obra que no podemos pensar si no en una costumbre que obedece a un convencimiento profundo y ha alcanzado un hondo arraigo personal. El transcurso de su obra es generalmente esperanzada, positiva, y alegre. Trías advierte un punto de inflexión en torno a 1907. Lo considera vinculado a lo que él ha mencionado como una crisis especial, llena de presentimientos. Pero no se trata de una pérdida de ese optimismo mencionado, sino de un matiz que éste adopta, haciéndose más espiritual, más cercano al infinito: «la consiguiente afirmación gozosa de todo lo que es visible y palpable, capaz de revelar lo invisible o impalpable [...] ir de lo bello a la sublime». 69

Uno de sus críticos, Maurici Serrahima, junto a su fuste intelectual, pondera la fundamentación metafísica de su pensamiento. En concreto, reconoce en la Oda Infinita el germen de toda una estética i su fundamento filosófico. Pero esta opinión no se manifiesta gratuitamente, sino que se ilustra con un ejemplo: «la reencontramos - la estética maragalliana- mucho más explícita, en el Elogi de la poesia donde se nos dice que Dios se revela.» Él mismo a través de la Naturaleza, dentro de la cual el hombre «representa todo el estado de conciencia divina que la tierra ha llegado a conseguir». ${ }^{70}$

66 Ibid., p. 307.

67 P. Maragall Mira, El «Cant espiritual», summa final o llindar d'un nou camí?, en J.M. Terricabras (ed.), Joan Maragall, paraula i pensament, op.cit., pp. 15-27.

68 «El derecho de hablar», O.C., Vol. X, p. 170.

69 E. Trías, El pensamiento de Juan Maragall, op.cit., p. 104.

70 M. Serrahima, Vida i obra de Joan Maragall. Barcelona: Bruguera, 1966, p. 41. (Original en catalán, traducción mía). 
De nuevo en concordancia con autores como Hölderlin, Schelling o Schiller; Maragall refleja su visión del mundo penetrado por Dios. La presencia de lo infinito en lo finito, y la unión del hombre y el mundo con la divinidad. Se trata de una «teoría teológica y cosmogónica porque lo que cierra el esquema es el hecho de que Dios es el origen de todas las cosas y que todas las cosas deben de volver a Dios. La cosmogonía determina, pues, la teleología. La vida tiene un sentido, que es el retorno a Dios.» ${ }^{71}$

Por otro lado, sin negar que estuviera afectado por el presentimiento de una muerte no muy lejana, esta visión más espiritual, que ve lo infinito en lo finito es típica de los autores de Jena y Maragall no deja de compartir y comunicar esa visión del mundo y de la vida. Moreta también señala la presencia de un «neoespiritualismo», típico del fin de siglo. ${ }^{72}$

\section{CONCLUSIONES}

La espiritualidad de Joan Maragall refleja una gran consonancia con autores del embrión de Romanticismo que es el Círculo de Jena. Sus lecturas de Goethe, Schiller, Schelling... dejan huella en su pensamiento y se reflejan especialmente en su obra en prosa. Los ejemplos más claros son los Elogios: breves ensayos escritos en su madurez que respiran el aire del idealismo, la esperanza, la elevación del espíritu y la presencia de algo divino en el ser humano.

Tanto sus escritos como los estudios que se han hecho de ellos, desde su fallecimiento hasta la actualidad, corroboran la presencia de estos elementos que nunca se han vinculado tan directa y claramente con ese grupo concreto de escritores y filósofos que inició la revolución romántica.

\section{REFERENCIAS BIBLIOGRÁFICAS}

ALLEGRA, G. 1980: Maragall traduttore e interprete di Novalis, Estratto da Giornale Italiano di Filologia, XI (XXXII) 2. Roma: Gadamo editore.

ALONSO, D. 1962: Cuatro poetas españoles. (Garcilaso, Góngora, Maragall, Antonio Machado). Madrid Gredos.

ARIMANY, M. 1963: Maragall 1860-1911. Barcelona: Ed. M. Arimany.

BACHS, J. 2001: Sobre el Cant Espiritual, (Col.lecció Quaderns de la Fundació Joan Maragall). Barcelona: Claret.

71 I. Moreta, «El pensament de l'últim Maragall» (1906-1911), op.cit., p. 304.

72 Cf. Ibid., p. 297. A pesar de que Moreta sitúa este espiritualismo en la etapa que él considera el segundo Maragall, lo encontramos presente en toda su obra, más allá de los elogios. 
BOU, E. 1997: La llum que ve del nord. Barcelona: Quaderns de la Fundació Joan Maragall.

BOU, E. 2011: «Amor redemptor? Visions urbanes de Joan Maragall». En J.M. Terricabras (Ed.), Joan Maragall, paraula i pensament. Girona: Documenta Universitaria Càtedra Ferrater Mora.

BOSCH, M. 2006: «Schelling i Maragall. Vida a l'art i a la paraula», Zeitschrift für Katalanistik, (19) pp.197-211.

CAIROL, E. 2000: Maragall i Novalis: poesia i experiència mística. Barcelona: Claret (Collecció Quaderns de la Fundació Maragall).

CORREDOR, JM. 1971: De casa i d'Europa. Barcelona: Selecta.

ESTELRICH, J. 1948: «Novalis y Maragall», Destino núm. 549, (14 de febrero).

FERRÁN, J. 1971: Los diálogos de Juan Maragall. (Colección vida y pensamiento españoles). Madrid: Ed. Nacional.

GRILLI, G. 1987: El mite laic de Joan Maragall, «El Comte Arnau». Barcelona: La Magrana, (Collecció: Els orígens).

GUITART-RIBAS, M. 1988: Influencias alemanas en la obra de Juan Maragall. Dissertation Information Service. The Catholic University of America: Washington D.C.

SOLDEVILA, C. 1930: «Pròleg» a Epistolari I. Obres Completes vol. IV. Barcelona: Edició dels fills.

LAÍN ENTRALGO, P. 1959: «Maragall y la esperanza», Separata de: Papeles de Son Armadans (Madrid-Palma de Mallorca).

MIRACLE, J. 1988: Joan Maragall poeta, pensador i home de fe. Barcelona: Fundació d'Història i Art Roger de Belfort (Collecció Tostemps).

MORETA, I, 2011: «El pensament de l'últim Maragall» (1906-1911), en Terricabras (Ed.), Joan Maragall paraula i pensament. Girona: Documenta Universitaria. Càtedra Ferrater Mora, pp. 283-314.

PLA, J. 1984: Joan Maragall un assaig. Destino: Barcelona 1984.

QUINTANA TRIAS, L. 1993: Estudi i edició de l' 'Elogi de la paraula'i l' 'Elogi de la poesia'. Bellaterra: Publicacions de la Universitat Autònoma de Barcelona. , 1996: La veu misteriosa. Barcelona: Publicacions de l'Abadia de Montserrat.

ROMEU FIGUEREAS, J. 1948: Modernisme i germanisme. Barcelona: Ariel.

RODRÍGUEZ BRAVO, JL 1987: Palabra y Paraíso: La meditación poética de Joan Maragall, Gabriel Miro y Juan Ramón Jiménez. Dissertation Information Service, University of Wisconsin: Madison 1987.

SABATÉ, M. 1935: «Un pròleg de Manuel de Montoliu», L’instant, 21 de mayo. SERRAHIMA, M. 1966: Vida i obra de Joan Maragall. Barcelona: Bruguera. 
TERRY, A. 1963: La poesia de Joan Maragall. Barcelona: Ed. Barcino.

TRÍAS, E. 1982: El pensamiento de Juan Maragall. Barcelona: Fundación Banco Urquijo i Edicions 62.

Magdalena Bosch Rabell es profesora de la Universitat International de Catalunya.

Líneas de Investigación:

Ética aristotélica, Estética del idealismo alemán

Publicaciones recientes:

2017: «La Noción de Ergon en el capítulo 7 del libro I de la Ética Nicomaquea», Cuadernos Salmantinos de Filosofia, vol. 44,

2017: «The role of intellectual Virtues in Decision maling», en A. J. G. Sison (ed.), Handbook of Virtue Ethics in Business and Management. Berlin: Springer.

Correo electrónico: mbosch@uic.es 